\title{
Association between Ramadan Fasting and cerebrovascular diseases
}

Accepted: $\mathbf{3 0 / 1 0 / 2 0 1 6}$

Abdullah Faky Yazdeen* Mutaz Fadhil Hummadi* Namir G. Al-Tawil** Ihsan K. AlShimmery* Srood N Jarjees*

\section{Abstract}

Background and objective: Cerebrovascular diseases are attacks of sudden neurological deficits (motor, sensory or cerebellar). There are a lot of risk factors for stroke like age, diabetes, hypertension, smoking, hyperlipidemia, cardiac diseases and others. This study aimed to show if there is increasing rate of cerebrovascular events during Ramadan in relation to fasting in our city during the summer season.

Methods: This case-control study was carried out in Rizgary Teaching Hospital, Erbil, Iraq from $1^{\text {st }}$ of August to $30^{\text {th }}$ of August 2011. Patients were included in this study if they were middle aged and elderly patients having clinical and radiological features of stroke, another group of in-patients was selected as a control group. Chi square test and logistic regression analyses were used to show the association between stroke and fasting.

Results: A sample of 60 patients and 60 control cases were included in this study. Fasting was significant risk factor for stroke in our studied sample, $66.7 \%$ of the cases were fasting compared with $40 \%$ of the control group $(P=0.03)$. Hyperlipidemia and history of ischemic heart disease found also to be associated with stroke $(P=0.017$ and 0.011 , respectively). Logistic regression analysis showed that only fasting and hypercholesterolemia were independent risks factors in causing stroke in our studied sample.

Conclusion: In Erbil, where the summer is too hot and the daytime (fasting hours) is long, fasting during Ramadan was found to be an independent risk factor for stroke, and specifically ischemic stroke.

Keywords: Ramadan; Fasting; Stroke; Summer season.

\section{Introduction}

Ramadan fasting is one of the five fundamental Islamic rules. Muslims fast for both eating and drinking and sexual contact from sunrise to sunset for complete one lunar month. Over one billion Muslims fast worldwide during the month of Ramadan. Fasting during Ramadan is a radical change in lifestyle for the period of a lunar month. ${ }^{1-4}$ The time of observance differs each year because it follows the lunar calendar, where the time periods corresponding to the month of Ramadan is different in every year according to the solar calendar, since the lunar calendar is 11-12 days shorter than the solar year. ${ }^{5}$ The fasting period from sunrise to sunset varies with the geographical site and seasons. In the summer months and northern latitudes, the fast can last up to 18 hours or more. At sunset, people usually eat a large meal, and have a rest or pray which in turn requires some efforts. Just before sunrise, people awake from sleep and have another rich meal. Then, some of them may pray and go to sleep again with a full stomach and some continue awake to practice their daily living programs. Fasting has some positive and probably negative effects on certain people; and especially sick people. The obligation that the daily calorie intake be taken in 1 or 2 meals instead of 3 to 5 has an adverse effect on certain people. An early morning walking to the mosque seems to be unwise for heart disease patients. ${ }^{6}$ Committed busy

* Department of Medicine, College of Medicine, Hawler Medical University, Erbil, Iraq.

** Department of Community Medicine, College of Medicine, Hawler Medical University, Erbil, Iraq. 
doctors in Erbil or whole Iraq may have additional obligations including the crowded afternoon clinic which may increase thirst feeling and hunger. The other probable negative effects are that while hungry patients cannot take any drug, such as antihypertensive or antiplatelet drugs, intravenous fluids and the regulation of diabetes mellitus is also negatively affected by an unfamiliar diet type. ${ }^{5}$ Moreover, during hot weather and in warm climates a higher possibility of haemo-concentration should also be considered. Although sick people are exempted from Ramadan fasting, most do not conform to this recommendation because of cultural factors. ${ }^{2}$ This study aimed to show the effect of Ramadan fasting on the rate of stroke in our population at Erbil city in the north of Iraq. We have chosen this year because Ramadan fasting occurred during the extremely hot weather (Mid Summer or August 2011) in which temperature in the shadow approached $50^{\circ} \mathrm{C}$ and even more at 1:00-4:00 PM. In addition, people should go to work in spite of that, and although people use modern technology for cooling, sometimes that is not enough to comply with the very hot and humid environment. To our knowledge, no previous study of this kind had been carried out in Iraq before, and studies tackling this subject are few, performed mostly in the nearby countries like Egypt, Qatar, Turkey and Iran.

\section{Methods}

A case-control study with a total sample of 120 respondents (60 patients and 60 controls) was carried out in Rizgary Teaching Hospital, Erbil- Kurdistan, Iraq. Data collection was done during Ramadan month of the year 2011 between $1^{\text {st }}$ of August to $30^{\text {th }}$ of August. Inclusion criteria for cases were any patient attending the emergency room of Rizgary Teaching Hospital during the mentioned period, complaining from clinical features of either acute weakness, sensory deficits, or features of brainstem deficits and radiological features of stroke obtained from the CT scan and MRI examinations. The machine was Siemens Single Slices Somatom Emotion with 4-8 $\mathrm{mm}$ slice thickness (Siemens Erlangen, Germany) and The MRI scanner was Siemens 1.5 tesla (Siemens, Erlangen, Germany). Control group was collected from the medical words, Rizgary hospital, at the same period, provided that they have no history of stroke or transient ischemic attack (TIA). A questionnaire was designed by the researchers to collect information about age, sex, known stroke risk factors including Hypertension, Diabetes Mellitus, smoking and Hyperlipidaemia which involves abnormally elevated levels of any or all lipids and/or lipoproteins in the blood and Hypercholesterolemia which means the presence of high levels of cholesterol in the blood. Information were also collected regarding the history of cardiac diseases ( AF, IHD, HF, pulmonary hypertension and others), previous stroke or TIA, drug history, and whether the patient is fasting or not. Data were analyzed using the statistical package for the social sciences (version 19). Chi square test of association was done to compare between proportions among cases and controls. Factors found to be associated with stoke (by Chi square test) were entered into a logistic regression model. A $P$ value of $\leq 0.05$ was considered statistically significant.

\section{Results}

A sample of 60 patients and 60 controls were studied with the female to male ratio of 1.3:1, 1.1:1 and mean $\pm S D$ ages of $62.24 \pm 12.7$, and $60.25 \pm 12.667$, respectively. Table 1 shows significant differences in the age distribution of cases and controls as the cases were relatively older than the controls. Around half $(46.7 \%)$ of cases were 70 years old or older $(P=0.037)$. Table 2 shows that $66.7 \%$ of the cases were fasting compared with $40 \%$ of the control group $(P=0.003)$. The same table shows that $71.7 \%$ of cases 
were hypertensive compared with $50 \%$ of ischemic heart disease also found of the controls $(P=0.003)$. Hyperlipidemia to be associated with stroke $(P=0.031$, including Hypercholesterolemia and history and 0.019 respectively).

Table 1: Age distribution of cases and controls.

\begin{tabular}{|c|c|c|c|c|c|c|c|}
\hline \multirow{2}{*}{ Age } & \multicolumn{2}{|c|}{ Cases } & \multicolumn{2}{|c|}{ Controls } & \multicolumn{2}{|c|}{ Total } & \multirow{2}{*}{$P$ value } \\
\hline & No. & $\%$ & No. & $\%$ & No. & $\%$ & \\
\hline$<50$ & 4 & 6.7 & 13 & 21.7 & 17 & 14.2 & \\
\hline $50-59$ & 10 & 16.7 & 13 & 21.7 & 23 & 19.2 & \\
\hline $60-69$ & 18 & 30 & 18 & 30 & 36 & 30 & 0.037 \\
\hline $70+$ & 28 & 46.7 & 16 & 26.7 & 44 & 36.7 & \\
\hline Total & 60 & 100 & 60 & 100 & 120 & 100 & \\
\hline
\end{tabular}

Table 2: Association of stroke with different factors.

\begin{tabular}{|c|c|c|c|c|c|c|c|}
\hline \multirow{2}{*}{ Variables } & \multicolumn{2}{|c|}{ Cases } & \multicolumn{2}{|c|}{ Controls } & \multicolumn{2}{|c|}{ Total } & \multirow{2}{*}{$P$ value } \\
\hline & No. & $\%$ & No. & $\%$ & No. & $\%$ & \\
\hline \multicolumn{8}{|l|}{ Fasting } \\
\hline Yes & 40 & 66.7 & 24 & 40 & 64 & 53.3 & \multirow[b]{2}{*}{0.003} \\
\hline No & 20 & 33.3 & 36 & 60 & 56 & 45.7 & \\
\hline \multicolumn{8}{|c|}{ Hypertension } \\
\hline Yes & 43 & 71.7 & 27 & 45 & 70 & 58.3 & \multirow[b]{2}{*}{0.003} \\
\hline No & 17 & 28.3 & 33 & 55 & 50 & 41.7 & \\
\hline
\end{tabular}

DM(both IDDM and NIDDM) ${ }^{* *}$

$\begin{array}{lccccccc}\text { Yes } & 22 & 36.7 & 20 & 33.3 & 42 & 35 & 0.702 \\ \text { No } & 38 & 63.3 & 40 & 66.7 & 78 & 65 & \\ \text { Hyperlipidemia } & & & & & & & \\ \text { Yes } & 19 & 31.7 & 9 & 15 & 28 & 23.3 & 0.031 \\ \text { No } & 41 & 68.3 & 51 & 85 & 92 & 76.7 & \end{array}$

History of Cardiovascular disease (IHD, AF and IHD, HF and IHD, HF, Pulmonary HT** others )

$\begin{array}{lccccccc}\text { Yes } & 20 & 33.3 & 9 & 15 & 29 & 24.2 & 0.019 \\ \text { No } & 40 & 66.7 & 51 & 85 & 91 & 75.8 & \\ \begin{array}{l}\text { Polycythemia } \\ \text { Yes }\end{array} & 0 & 0 & 1 & 1.7 & 1 & 0.8 & 1^{*} \\ \text { No } & 60 & 100 & 59 & 98.3 & 119 & 99.2 & \\ \text { Smoking } & & & & & & & \\ \text { Yes } & 8 & 13.3 & 11 & 18.3 & 19 & 15.8 & \\ \text { No } & 38 & 63.3 & 32 & 53.3 & 70 & 58.3 & \\ \text { Ex-smoker } & 14 & 23.3 & 17 & 28.3 & 31 & 25.8 & \end{array}$

History of Alcohol consumption before Ramadan

\begin{tabular}{lccccccc} 
Yes & 1 & 1.7 & 2 & 3.3 & 3 & 2.5 & $1^{*}$ \\
No & 59 & 98.3 & 58 & 96.7 & 117 & 97.5 & \\
$\begin{array}{l}\text { Previous Stroke } \\
\text { Yes }\end{array}$ & 10 & 16.7 & 0 & 0 & 10 & 8.3 & $0.001^{*}$ \\
No & 50 & 83.3 & 60 & 100 & 110 & 91.7 & \\
Previous TIAs* & & & & & & & \\
Yes & 9 & 15 & 0 & 0 & 9 & 7.5 & 0.003 \\
No & 51 & 85 & 60 & 100 & 111 & 92.5 & \\
\hline
\end{tabular}

* By Fisher's exact test

${ }^{* *} \mathrm{HT}=$ hypertension, $\mathrm{DM}=$ diabetes mellitus, IDDM= insulin dependent diabetes mellitus, NIDDM= non-insulin dependent diabetes mellitus, $\mathrm{IHD}=$ ischemic heart disease, $\mathrm{AF}=$ atrial fibrillation, $\mathrm{HF}=$ heart failure, $\mathrm{TIA}=$ transient ischemic attack. 
Logistic regression analysis (Table 3 ) lacunar), only $7 \%$ was hemorrhagic stroke showed that only fasting and hypercholesterolemia are significantly associated with stroke $(\mathrm{OR}=3.8$ and 11.2 respectively). The pathological cause of stroke in $93 \%$ of our studied sample was ischemia (embolic, thrombotic and and $77.4 \%$ of the ischemic types was anterior circulation stroke while the posterior circulation stroke represents the remaining $22.6 \%$ of patients as shown in Table 4.

Table 3: Logistic regression analysis between stroke as a dependent variable and several covariates.

\begin{tabular}{lccccc}
\hline \multirow{2}{*}{ Independent variables } & B & P value & OR & \multicolumn{2}{c}{$95 \%$ Cl for OR } \\
& & & & Lower & Upper \\
\hline Fasting & 1.341 & 0.003 & 3.821 & 1.558 & 9.374 \\
Hypertension & 0.731 & 0.110 & 2.077 & 0.848 & 5.084 \\
Hyperlipidemia & -0.087 & 0.901 & 0.917 & 0.232 & 3.620 \\
Hypercholesterolemia & 2.417 & 0.020 & 11.213 & 1.456 & 86.378 \\
History of Cardiac Diseases & 1.003 & 0.056 & 2.726 & 0.974 & 7.625 \\
Age (years) & & 0.073 & & & \\
$<50$ (reference) & & & & & \\
$50-59$ & -0.113 & 0.894 & 0.893 & 0.169 & 4.726 \\
$60-69$ & 0.475 & 0.543 & 1.608 & 0.348 & 7.422 \\
$\geq 70$ & 1.400 & 0.064 & 4.057 & 0.923 & 17.826 \\
Constant & -2.255 & 0.001 & 0.105 & & \\
\hline
\end{tabular}

Table 4: Distribution of cases by type of stroke.

\begin{tabular}{lcc}
\hline & No. & Percent \\
\hline Type of stroke $(\mathbf{n}=\mathbf{5 7})$ & 53 & 93 \\
Iscemic & 4 & 7 \\
Hemorrhagic & & \\
Type of ischemic stroke $(\mathbf{n}=\mathbf{5 3})$ & 41 & 77.4 \\
Anterior circulation & 12 & 22.6 \\
Posterior circulation & 12 \\
\hline
\end{tabular}




\section{Discussion}

God had mentioned in the Holy Quran that people should not fast if they are sick or traveling and instead, they can pay to feed poor people or postpone fasting to any other day in the year (The Holly Quran, Al-Bakara, Aya 182-185). A study with larger sample size would lead to a better data analyses and findings. In this study, we had observed that fasting at summer time in Erbil governorate significantly affecting the rate of cerebrovascular accidents especially in high risk patients (hypertensive, hyperlipidemic and mostly hypercholestrolemic, smoker, and those with history of previous Ischemic heart disease, strokes and transient ischemic attacks) according to chi square test while using logistics regression analysis test had proved that fasting and hypercholesterolemia were the only independent risk factors observed in causing cerebrovascular events during fasting at Ramadan. That was on the contrary to the findings of Bene ${ }^{1}$ and his colleagues in which he did not find any difference in stroke incidence after reviewing hospital records over 13 years at Qatar which may have nearly the same hot and humid environment like our country. But we would stress that Qatar is more developed country especially in the health system and cooling technology than our country and the method and design of the study were different than that of our study. Akhan et al. ${ }^{4}(2000)$ also reported no increase in the incidence of hospitalization of stroke cases during Ramadan mostly because he performed his study in Isparta where the environmental factors are quite different than that of our region. Nearly the same results mentioned by Ahmad Chistaz and his colleagues ${ }^{7}$ in Iran, in which he studied the rate of stroke between fasting and nonfasting population and no significance difference was observed over two years, possibly because Iran is a different country than Iraq regarding its weather. Ince et al. ${ }^{8}$ (1997) and Kutluhan et al. $^{9}$ (1996) did not find a significant
Increase in stroke incidence in their studies, but these studies were done in Turkey which is a more colder country than Iraq, and they are old studies if we consider the effect of global warming that increased in the last few years. Selcuk and his colleagues ${ }^{2}$ found that stroke incidence would increase in diabetic patients during Ramadan significantly although the overall incidence for all other variables was not significantly different if compared to different months in the year. According to Jeffrey and his colleagues ${ }^{15}$ dehydration and hyper viscosity had been included with the risk factors of strokes, We also believe that hemoconcentration had increased the incidence of stroke in collaboration with other factors and that we should have special tool to measure it in those patients suffering thirst and dehydration for about 16 hours in such hot climate while they were fasting. A relatively new study, presented at Chicago at the 2008 American Academy of Neurology $60^{\text {th }}$ (AAN) Anniversary Annual Meeting, shows that prolonged fasting may cause heart problems especially a certain type of heart attack during Ramadan fasting at Iran. More specifically, the new study presented at the AAN Meeting focused on a very specific type of stroke (cerebral venous sinus thrombosis) that usually developed by women and young adults and children mostly due to dehydration, and contraceptive pills use that was regularly used by some fasting women to delay their menstrual cycle and having it just after finishing fasting of the whole month, since menstruating woman should not fast or pray during the month according to the Islamic regulations and this would lead to more hypercoagulable state due to both fasting and contraceptive pills. ${ }^{10}$ Ischemia was the commonest pathological cause $(93 \%)$ of stroke observed in our studied sample, and although it was expected to be the most common cause of stroke worldwide, but the percentage was higher than the documented figures in textbooks and literature (about 80\% ischemic, 20\% 
different types of intracranial hemorrhage $)^{11}$ may be because of relative added risk of hemoconcentration and metabolic derangements expected to happen during fasting especially in high risk patients like Diabetics and elderly hypertensive patients and those already had bad past medical history like previous stroke, TIAs and Ischemic heart disease. But the reverse also may be true in that the incidence of hemorrhagic stroke may decrease during Ramadan time as proved by Salcuk and his colleagues $^{2}$ which can be explained physiologically due to inhibition of catechol amines during hunger period leading to decrease venous return and subsequently reduction in sympathetic tone leading to reduction in blood pressure which is the main cause of hemorrhagic stroke. ${ }^{12-14}$

\section{Conclusion}

The study showed a significant association between fasting Ramadan and stroke. More research is needed in this field considering more sample size and different study designs.

\section{Conflicts of interest}

The authors report no conflicts of interest.

\section{References}

1. Bener A, Hamad A, Fares A, Al-Sayed HM, Al-Suwaidi J. Is there any effect of Ramadan fasting on stroke incidence? Singapore Med J 2006; 47(5):404-8.

2. Omouglu S, Temuzhan A, Pesuncu E, Tandouan $U$, Ozbakir S. Effects of Ramadan Fasting on Stroke. Turk J Med Sci 2003; 33:237-41.

3. Al Suwaidi J, Bener A, Al Binali H, Numan MT. Does hospitalization for congestive heart failure occur more frequently in Ramadan: a population based study (1991 - 2001). Int J Cardiol 2004; 96:217-21.

4. Akhan G, Kutluhan S, Koyuncuoglu HR. Is there any change of stroke incidence during Ramadan. Acta Neurol Scand 2000; 101:259-61.

5. Bener A, Galadari S, Gillett M, Osman N, Al-Taneiji $\mathrm{H}$. Fasting during the holy month of Ramadan does not change the composition of breast milk. Nutrition Research 2001; 21:85964.

6. Aslam M, Assad A. Drug regimens and fasting during Ramadan. A survey in Kuwait. Public Health 1986; 100:49-53.
7. Chitsaz A, Ashtari F, Sadeghian M, Farajzadegan $Z$. The relation between Ramadan fasting and stroke incidence over a two year study. Journal of Isfahan Medical School, Special Issue on Health Promotion 2009; 26:605-13.

8. Ince B, Turgut N, Celik Y, Denktas H. Effect of Ramadan on occurrences and prognosis of stroke. J Turkish Association Neurology 1997; 3: 68.

9. Kutluhan S, Sandilkci Y, Aytekin S. The Relationship of Ramadan with Cerebrovascular Diseases. J Vakif Gureba Hospitals 1996; 21:26974.

10. Saadatnia $M$, Zare $M$, Fatehi $F$, Ahmadi $A$. The effect of fasting on cerebral venous and dural sinus thrombosis. Neurol Res 2009; 31(8):794-8.

11. Sacco RL. Vascular disease: Pathogenesis, Classification and Epidemiology of Cerebrovascular disease. In: Rowland LP editor. Merrit's Neurology. $11^{\text {th }}$ ed. Philadelphia (PA): Lippincott Williams and Wilkins; 2005. p. 275-91.

12. Temizhan A, Donderici O, Oguz D, Demirbas B. Is there any effect of Ramadan fasting on acute coronary heart disease events. Int J Cardiol 1999; 70:149-53.

13. Young JB, Landsberg L. Impaired Suppression of Sympathetic Activity during Fasting in the Gold Thioglucose-treated Mouse. J Clin Invest 1980; 65(5):1086-94.

14. Stokholm Kh, Berum L, Astrup A. Cadiac Contractiliy, Central hemodynamics and Blood Pressure during Semi starvation. Clin Physiol 1991; 11:513-23.

15. Cohen J, Fadul C, Jenkyn L, Ward T. Disorders of the Nervous System-Reeves \& Swenson. $2^{\text {nd }}$ ed. Dartmouth Medical School: Reeves A G; 2009. 